\title{
Effects of Human Wetland Encroachment on the Degradation of Lubigi Wetland System, Kampala City Uganda
}

\author{
Omagor James Gideon', Barasa Bernard ${ }^{2, *}$ \\ ${ }^{1}$ Department of Environmental Management, Makerere University, P.O. Box 7062 Kampala, Uganda \\ ${ }^{2}$ Department of Geography and Social Studies, Kyambogo University, P.O. Box 1 Kyambogo Kampala, Uganda
}

Copyright $\odot 2018$ by authors, all rights reserved. Authors agree that this article remains permanently open access under the terms of the Creative Commons Attribution License 4.0 International License

\begin{abstract}
The biggest threat to wetland ecosystems in Kampala is posed by increasing and dimensionless anthropogenic activities that infringe and transform them biologically, often for short-term human consumptive purposes. The principal objectives of this study were to examine the extent of wetland temporal changes between 2000 and 2018 and to establish the causes and consequences of human wetland encroachment. Geographical Information Systems and Remote sensing techniques were used to analyze high-resolution satellite imagery captured during 2002, 2015 and 2018, coupled with ground surveys involving interactions among wetland communities. Our results reveal that the areas covered by diverse wetland vegetation in 2002 represented $96.3 \%$ of the total land cover which was the largest, this gradually decreased to $82.5 \%$ in 2015 and finally $80.6 \%$ in 2018 . There was a general increase in Murrum (laterite soil) deposited areas within the wetland system. Smallholder agricultural lands also increased from $0.2 \%$ in 2002 to $1.6 \%$ in 2015 and $7.7 \%$ in 2018. Settlements also experienced an increase from $3.2 \%$ to $7.8 \%$ in 2015 . The encroachments are mainly driven by high population pressure, inadequate enforcement of wetland regulations and political interventions. The wetland extent is narrowing at a high rate due to settlements. This process is broken into phases: depositing of murram or tree planting or farming activities and later settlements. This study demonstrates more shortfalls in the monitoring mechanisms of wetland conservation and wise use in Kampala.
\end{abstract}

Keywords GIS, Land Use/Cover, Kampala, Lubigi, Encroachment

\section{Introduction}

The wetlands function as essential environmental components and are vital natural resources, which provide ecological, economical, socio-cultural, scientific and recreational services to the country. Other wetland functions include breakage of toxic compounds after absorption by wetland plants, prevention of soil erosion by reducing the velocity of flow allowing silt to settle and reduction of siltation in water bodies as identified by Samarasinghe \& Dayawansa [1]. Barbier et al., [2] also noted that by recycling nitrogen, wetlands improve the water quality of downstream water bodies. Wetlands absorb the excess water of rivers and streams in heavy rain periods and delay its release. Thus, they provide social and economic values to humans by controlling flood. Wetlands in Uganda cover about $13 \%$ or $30,000 \mathrm{~km}^{2}$ of the country and include areas of seasonally flooded grassland, swamp forest, permanently flooded papyrus and grass swamp and upland bog.

Direct support to livelihood takes a variety of forms but involves in most cases the extraction of natural wetland products like water for agriculture and livestock, fish, clay, medicine, sand and vegetation. Although these products contribute considerably to rural income, a far more valuable contribution of wetlands to rural livelihoods is made by their services, like water distribution in times and space, microclimate amelioration, and ecological stability as stated by the Wetlands Management Department Uganda (WMD). Altogether, the goods, services and attributes constitute a considerable ecological, social and economic value, which may be lost when wetlands are converted or altered. Wetlands are definitely not wastelands as they were previously viewed but wealth lands contributing to the gross national product both visible and more intangible benefits.

Bwogi [3] noted that wetland reduced from 15\% in 1994 to $10.9 \%$ of Uganda's area accounting for the increase in land degradation. Land degradation can be defined as a "Reduction or loss of the biological or economic productivity and complexity of rainfed cropland, irrigated cropland, or range, pasture, forest and woodlands resulting from Land Use/Covers or from a process or combination of processes, including processes arising from human activities and habitation patterns, such as: (i) soil erosion 
caused by wind and/or water; (ii) deterioration of the physical, chemical and biological or economic properties of soil; and (iii) long-term loss of natural vegetation" as defined by United Nation Convention to Combat Desertification (UNCCD).

Abebe [4] defined GIS as a tool used for systematic spatial data collection and processing. It can be used to study the environment by observing and assessing the changes and forecasting the future based on the existing situation. Modern GIS gives users the ability to conduct visual and quantitative analysis involving multiple kinds of digital spatial data, including remotely sensed imagery. Remote sensing (RS) and geographic information system (GIS) have previously been used as tools for advanced ecosystem management in collecting remotely sensed data that can facilitate synoptic analyses of Land Use/Cover patterns, and changes and projecting it to global scales over time. Remote sensing technologies can provide up-to-date spatial and temporal information about wetlands, Ozesmi et al., [5], thereby contributing to sustainable wetland management. The GIS data that has been collected in the study will be important reference information. Considering the problems that pop up due to human encroachment that is resulting into the degradation of wetlands countrywide, this study has examined temporal changes in wetland size in Lubigi system and evaluated the causes and consequences of wetland encroachment.

\section{Materials and Methods}

\subsection{Study Area}

Lubigi is located on the northwest side and is part of a system in which waters flow north towards Lake Kyoga. Lubigi wetland is the largest of all the remaining wetlands in Kampala city and it is a tributary to Mayanja-Kato system in the north and receives water from Nsoba wetland system. Lubigi is found in Rubaga and Kawempe sub-counties and is $7.5 \mathrm{~km}$ west of Kampala City Center. Masaka, Mityana, Hoima, and Sentema roads all cross through this wetland. According to Maidment et al., [6], the southern part of Uganda including Kampala has two distinct rainfall seasons (February to June and August to November) coinciding with the northward and southward passage of the ITCZ (Intertropical Convergence Zone). Kampala city, and the study area is located in the Lake Victoria basin climatic zone, which receives between $1200-2000 \mathrm{~mm}$ per year. Most of the natural vegetation has been cleared due to man's activities especially in the northern part of the wetland and much of the southern part is still intact. However, the area under natural vegetative cover has considerably reduced. The natural vegetation has been cleared through cultivation, road construction, settlements and collection of building materials and for the building sites. Originally, the valley swamps were dominated by Cyperus papyrus sedges. Lubigi wetland is dominated by papyrus and it is noted that papyrus is known to increase the action of nitrifying bacteria on wastewater. [7 p.453]

\subsection{Satellite Images}

Satellite images of 2002, 2015, and 2018 from Google Earth Pro Software have been used in this study. The images were geo-referenced to the Uganda National Coordinate System - Universal Traverse Mercator (UTM) Projection and Arc 1960 datum using Arc GIS 10.1 software. UTM coordinates are easy to use and they work with almost all GPS devices. Also, UTM covers most of the world. The system uses meters as its base unit, which makes conversions and measurements easier and that accounts for the reason of transforming our images to this kind of coordinate system.

\subsubsection{Image Preparation}

Images suitable for observation were acquired from Google Earth Software for the years 2002, 2015 and 2018. The images were obtained at a scale of 1:26,245 and for each year, these were taken during the day periods, which allows for a reliable comparison of the specific land cover types.

All the images have been processed using ArcGIS software 10.1, rectified and projected to the Uganda National Coordinate System -Universal Traverse Mercator (UTM) Projection and Arc 1960 datum using Arc GIS 10.1 software.

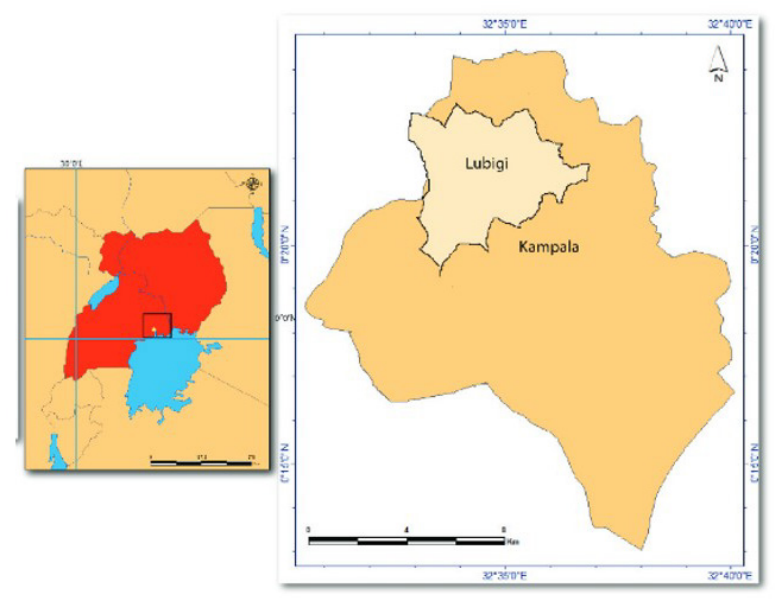

Figure 1. Map of Uganda (Left), showing the location of Kampala District which has been extrapolated on the Right to show the location of Lubigi

\subsubsection{Digitizing}

This is the process of interpreting and converting paper 
map or image data to vector digital data. As we transformed the image data we generated shapefiles based on the downloaded images and this was utilized to classify the different forms of encroachment on the wetland ecosystem hence coming up with digitized maps for the different years showing the effect of encroachment on the spatial-temporal changes of the wetland. On-screen digitizing in Arc Map Software was used for this study because it often reduces both interpretation and digitizing errors and makes work simpler. The different forms of encroachment on the wetland were classified into different Land Use/Cover classes as shown in Table 1. After doing Land Use/Cover classification, the accuracy of special data is necessary to be defined. Accuracy assessment or validation is an important step in the processing of remote sensing data which determines the information value of the resulting data to a user. Land Use/Cover analysis can be done from processed satellite images (Landsat image, Quick bird image) and Google Earth. Since remotely sensed data from the earth orbit can be obtained repeatedly over the same area, they have been very useful to monitor and analyze LUCC in various regions of the earth and greatly contribute to planning and management of available resources, especially in the developing countries where other kinds of background data are often lacking [8]. Beside Google Earth, map data and positional measurement can be obtained using different methods such as conventional or modern land survey methods, Global Positioning System (GPS) and remote sensing satellite imagery. Each of these methods is of a known positional accuracy. Potere [9] notes that an assessment of the positional accuracy of Google Earth imagery would require a comparison between known points and the corresponding points as displayed by the Google Earth application, for instance the used four control points from 109 cities each where high-resolution Google Earth imagery is available and then compared these to their corresponding positions in the GeoCover data set, which he notes has the "positional accuracy of 50 meters root-mean-squared error (RMSE)"

\subsection{Research Design}

In order to establish the causes and consequences of human encroachment on the degradation of the study, this section of the research was based on a cross-sectional survey design, information concerning the causes and consequences of encroachment and people's perceptions regarding the state of the wetland was collected using questionnaires and review of past findings supplemented by direct observation and photographic interpretation. A cross-sectional survey was used in this research study because studies on the effects of wetland encroachment on both socio-economic welfare and spatial extent of the wetland could best be established by direct communication between the researcher and respondent. Under these circumstances, the researcher is able to focus questions to enable respondents to understand them, and therefore minimizing errors in response. Hence this survey method of research was the most suitable method of acquiring this kind of data. Since it is practically expensive and time consuming to interview the whole population, samples of people in various categories were used. The views, perceptions and ideas generated can be generalized to apply to the whole population, hence the reason for adopting a cross-sectional survey. A sample size of 66 respondents was used because it was manageable in terms of researcher's financial resources. For the case of sampling frame and sample selection, the research was carried out based on a combination of purposeful and multistage random sampling. The questionnaire was designed by the researcher and it included both open-ended and closed questions clearly stated in English since the researcher was well versed with the local language (Luganda). The questionnaire - covered questions on variables like causes of wetland encroachment, consequences resulting from land use/cover changes and all these were ranked by the respondents.

Table 1. The land use/cover type's classification system used for Lubigi wetland system

\begin{tabular}{|c|c|}
\hline Land use/cover Class & Description \\
\hline Settlements & Urban or built-up land consisting of residential areas, slums and tenements \\
\hline Agricultural Lands & $\begin{array}{c}\text { Areas of land prepared for growing agricultural crops. This category includes } \\
\text { areas currently under crop and land under preparation. Crops include yams, } \\
\text { sugar canes, maize, etc. }\end{array}$ \\
\hline Road Network & These include both main roads, highways and feeder roads. \\
\hline Murrum Deposits & Lands with exposed soil, sand or rocks, and has less than 10\% vegetated cover. \\
\hline Treatment Plant & $\begin{array}{c}\text { The National Water and Sewerage Cooperation water treatment plant facility } \\
\text { within the catchment area. }\end{array}$ \\
\hline Tree Patches & Areas within the catchment area with artificial trees planted typically for sale \\
\hline Wetland Vegetation & Areas covered by papyrus, shrubs, thickets and all naturally existing wetland \\
plants.
\end{tabular}




\section{Results and Discussions}

For the first objective of examining the size of the wetland temporal changes in Lubigi, a series of digitized maps were prepared using the collected data. These features indicated changes in agricultural lands, tree patches, roads, etc. A classification system of seven Land Use/Cover types were developed for the purposes of the study and identified and delineated boundaries of polygons of the categories. The description of these types is shown in Table 1 .

\subsection{Land use/cover Changes}

For the years 2002, 2015 and 2018, the Land Use/Cover area coverage were as follows; areas covered by wetland vegetation in 2002 was $96.3 \%$ of the total land cover which was the largest, this gradually decreased to $82.5 \%$ in 2015 and finally $80.6 \%$ in 2015 . There was a general increase in Murrum deposited areas within the wetland. Agricultural lands increased from $0.2 \%$ in 2002 to $1.6 \%$ in 2015 and finally to $7.7 \%$ in 2015 which was the second largest of the total Land Use/Cover. Settlements also experienced an increase from $3.2 \%$ to $7.8 \%$ in 2015 .

In the period of 2002 to 2015, the highest Land
Use/Cover change rate was experienced in wetland vegetation at $13.8 \%$ followed by tree patches at $-1.4 \%$. The area covered by the treatment plant experienced a fall back to $-2.1 \%$ and $-0.4 \%$ respectively. Between 2015 and 2018 the highest Land Use/Cover change rate was experienced in settlement areas at $5.4 \%$, this was followed by wetland vegetation, Murrum deposits at $1.9 \%$, and $0.1 \%$. The change rate for agricultural lands fell by $-6.1 \%$ of the land cover. Table 2 illustrates the trend in Land Use/Cover change from 2002 to 2018 .

From the quantitative analysis in Table 3, the extent of coverage of the wetland vegetation experienced a percentage change from 13.8 between years 2002 and 2015 to a percentage change of 1.9 in years between 2015 and 2018. This rapid change can be explained by the increase in the percentage change of deposited Murrum from -5.1 to $0.1 \%$ respectively hence accounting for the loss of wetland vegetation. From the above results, it is evident that human encroachment has greatly impacted on the spatial extent of the wetland ecosystem. These anthropogenic processes have greatly resulted into the reduction of the wetland. This is also true as recorded in previous studies; Lubigi wetland reduced from $7.02 \mathrm{~km}^{2}$ to $4.38 \mathrm{~km}^{2}$ with only $62.4 \%$ of the wetland still intact in 2015 [10].

Table 2. Land use/cover area (sq. m) for the time period 2002-2018

\begin{tabular}{|c|c|c|c|}
\hline \multirow{2}{*}{ Land Use } & \multicolumn{3}{|c|}{ Area $\left(\mathrm{m}^{2}\right)$} \\
\cline { 2 - 4 } & $\mathbf{2 0 0 2}$ & $\mathbf{2 0 1 5}$ & $\mathbf{2 0 1 8}$ \\
\hline Tree Patches & 8613.931 & 28438.245 & 52168.91 \\
\hline Treatment Plant & 0 & 63865.132 & 78080.14 \\
\hline Murrum deposits & 0 & 157963.07 & 154703.7 \\
\hline Agricultural Lands & 7021.533 & 48605.365 & 234743.6 \\
\hline Settlement & 97545.78 & 241277.42 & 74419.95 \\
\hline Wetland Vegetation & 2957980.86 & 2534508.21 & 2468574.5 \\
\hline
\end{tabular}

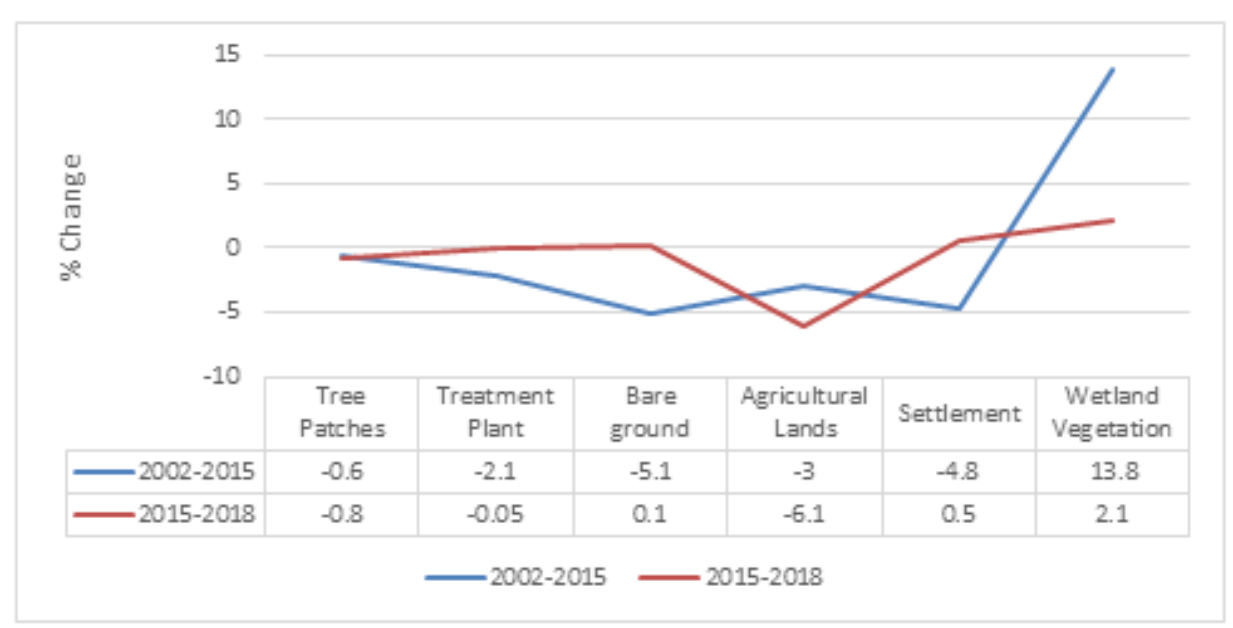

Figure 2. The trend of temporal land use/cover area extent (\%) change for the system as derived from the classification of satellite imagery of Lubigi wetland for the period 2002-2018 
The earliest satellite images of part of the wetland catchment area stretching from Setema Road to Bwaise were used for this study. In 2002, most parts of the wetland especially in Nabweru and off towards Nansana on Hoima Road were intact including the southwestern parts, except for settlements in Bwaise where population explosion from the catchments had pushed the settlements into the wetland. This also accounts for the lack of the treatment plant and Murrum deposits in the initial year (2002). Currently, there is also pressure on the wetlands for settlements in Nabweru and Nansana and in other southwestern parts of the wetland. In 2002, a great percentage of the wetland was still intact and remained in the undisturbed state till 2003, Mhonda [10]. From this study, in 2002, 94.71\% of the wetland was still intact. Only 5.29\% of the wetland had been disputed to a less extent by roads, settlements and a few other activities of negligible impact.

Table 3. Changes of land use/cover area (\%) and annual change computations in the study area for the time period 2002-2018

\begin{tabular}{|c|c|c|c|c|c|c|c|c|}
\hline \multirow{3}{*}{ Land Use/Cover } & \multicolumn{6}{|c|}{ Area (Sq. m) } & \multicolumn{2}{|c|}{$\%$ Changes } \\
\hline & \multicolumn{2}{|c|}{2002} & \multicolumn{2}{|c|}{2015} & \multicolumn{2}{|c|}{2018} & \multirow[b]{2}{*}{ 2002-2015 } & \multirow[b]{2}{*}{ 2015-2018 } \\
\hline & & $\%$ & & $\%$ & & $\%$ & & \\
\hline Tree Patches & 8613.93 & 0.3 & 28438.25 & 0.9 & 52168.91 & 1.7 & -1.4 & -0.8 \\
\hline Treatment Plant & 0.0 & 0 & 63865.13 & 2.1 & 78080.14 & 2.5 & -2.1 & -0.4 \\
\hline Murrum deposits & 0.0 & 0 & 157963.07 & 5.1 & 154703.68 & 5.1 & -5.1 & 0 \\
\hline Agricultural Lands & 7021.53 & 0.2 & 48605.37 & 1.6 & 234743.55 & 7.7 & -7.5 & -6.1 \\
\hline Settlement & 97545.79 & 3.2 & 241277.42 & 7.8 & 74419.95 & 2.4 & -4.6 & 5.4 \\
\hline Wetland Vegetation & 2957980.86 & 96.3 & 2534508.21 & 82.5 & 2468574.5 & 80.6 & 13.8 & 1.9 \\
\hline TOTAL & & 100 & & 100 & & 100 & & \\
\hline
\end{tabular}
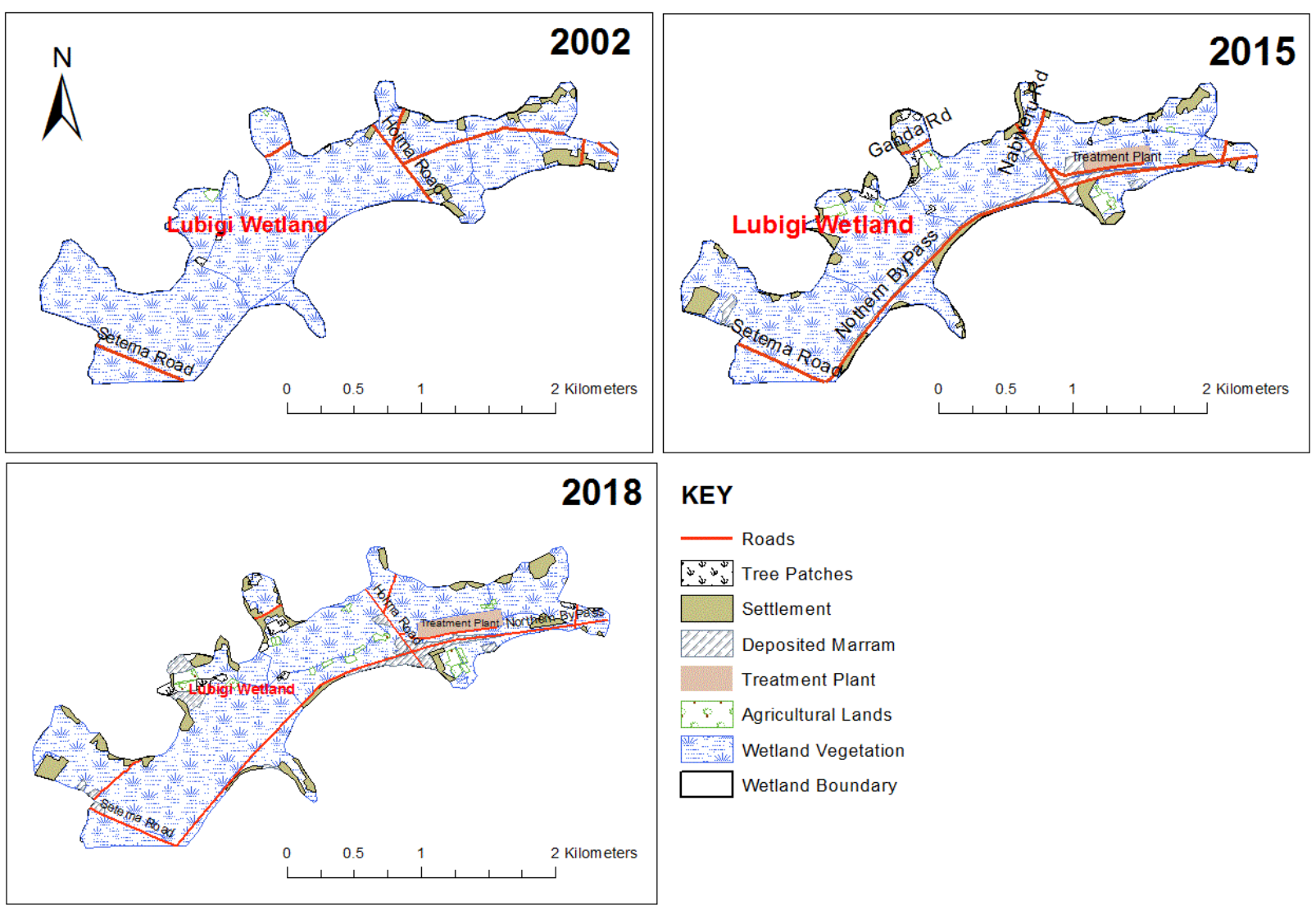

Figure 3. Land use/cover extent changes during 2002-2018 
By the beginning of January 2015, the sewerage treatment plant of National Water and Sewerage Corporation (NWSC) had been constructed and it occupied $1.16 \%$ of the wetland. According to the same paper by Mhonda [10]. The road network had increased due to the expansion of the Northern bypass and construction of part of Entebbe express highway that enters into the Lubigi wetland, however, most of the road network was constructed through the infringes of the wetland. In 2015, fish farming, which has been categorized under Agricultural Lands, also greatly increased.

As part of the Kampala sewerage Master Plan, the National Water and Sewerage Corporation established a sewerage treatment plant in the middle of Lubigi wetland to serve Northern Kampala. The plant has a combined treatment capacity of 5400 cubic meters of wastewater per day. It receives and treats wastewater from the piped network as well as fecal sludge that is brought by private cesspool emptier trucks. The Lubigi catchment area consists of Makerere, Katanga, parts of Mulago, Kalerwe, Bwaise and areas along the northern by-pass. The most significant estimated change of Lubigi wetland during the selected years is the decrease of the vegetation areas that have been seriously reduced from their initial extent (96\%) and the increase of agricultural lands and settlement areas (Table 3).

\subsection{Causes and consequences of wetland encroachment}

The probable causes to wetland encroachment as noted based on people's perceptions were ranked by the sampled population and these causes included political, institutional and social causes as shown in table 4 below. The most significant causes have been discussed as follows;

Population explosion; the increased population is significantly marked with an insatiable desire of both the rich and the poor to derive their livelihoods from the wetlands including the desire for industrial expansion. In urban areas, particularly Kampala, wetlands such as Lubigi are seen as the cheapest areas for industrial development. Hence converted to institutional or agricultural use, or have gradually been taken over by the semi-slum residential housing and associated uses, such as cultivation, waste disposal or business sites for local manufacturing artisans.

Political Intervention; whereas wetlands are held in trust by Central Government or Local Government for the common good of the people of Uganda, recent examples of wetland abuse have included cases where local authorities have been the very violators of this constitutional provision. Where this has happened, Central and Local Authorities have indicated that they converted wetlands for the sake of providing their communities with economic growth opportunities and for fighting poverty as per Government Policy (PEAP). It is, therefore, a dilemma that the very institutions entrusted with the protection of wetlands have in some cases not assisted the crusade for their conservation. For example; it has been noted that there is massive involvement of Local Councils (LC) in the sale of wetlands in many parts of the country. In Kinawataka wetland located between Kampala and Wakiso districts, the Chairperson of Kinawataka village, Mbuya Zone IV, Kasokoso and Kitintale Zone 12 in Nakivubo wetland and in Namungona area in Lubigi wetland were involved in the witnessing and illegal selling of wetlands. The government, therefore, cannot get any significant and consistent cooperation and support from these environmental managers (LC1) who are closer to the wetland and support to be more effective.

Lack of Institutional Arrangement; as wetlands are a source of water, biodiversity and related resources, they attract a number of stakeholders that deal directly or indirectly. There is a need for a coordinator that harmonizes the relationship among the stakeholders and sets better management of wetlands. An example, in Ethiopia different stakeholders, local communities, governmental and non-governmental organizations use wetlands in an uncoordinated manner and this approach is affecting the vigour of wetlands and speeding up their degradation as mentioned by Tietenberg [10]. As a result, wise use of wetlands has not yet given proper attention and priority. Different users view wetlands from their own perspective and institutional objective. For instance, agriculturalists see moist fertile soil with vast potential for growing grain; fishery managers find a support base for producing fish; hydrologists calculate capacities to provide water for industry, agriculture, and domestic use; public health specialists may see them as regulators of water quality or in contrary as transmitters of diseases such as malaria; and so on. Investment in wetland management is rarely integrated. Instead, wetlands are invariably viewed by each user as single-product systems, precluding other values, while single purpose returns fall far short of expectations. The absence of an institution duly empowered to issue and implement wetland laws and coordinate management activities is the underlying cause for the deterioration of the wetlands of Ethiopia.

Capacity shortage; wetland management in Uganda also suffers from capacity limitations such as lack of skilled manpower, finance and technology. Wetland focused training programmes are very scarce at the institutional level. Programmes are not implemented to fill this gap nationally. As a result, there is a shortage of wetland specialists. There is also awareness problem from grassroots up to decision maker level. The scarcity of wetland focused institutions and the weak relation of the country to wetland affiliated global institutions such as the Ramsar Secretariat has hampered its capacity building opportunities. 
Table 4. Probable causes to wetland encroachment based on people's perceptions.

\begin{tabular}{|c|c|c|}
\hline \multicolumn{2}{|c|}{ Probable Causes to encroachment } & Tot. Rank \% \\
\hline \multirow{3}{*}{ Political } & Poor implementation strategies of laws & 6.5 \\
\cline { 2 - 3 } & Political Interventions & 11.3 \\
\hline \multirow{3}{*}{ Institutional } & Capacity Shortage & 9 \\
\cline { 2 - 3 } & Poor institutional arrangements & 0.2 \\
\cline { 2 - 3 } & Infrastructural developments e.g.; roads, buildings & 23 \\
\cline { 2 - 3 } & Discharges (toxicants of domestic sewage, ) & 3.2 \\
\hline \multirow{3}{*}{ Social } & Drainage for settlement & 22.6 \\
\cline { 2 - 3 } & Pollution of all forms e.g. from industries & 5 \\
\cline { 2 - 3 } & Drainage for agriculture, forestry & 9.4 \\
\cline { 2 - 3 } & Harvesting of wetland resources e.g.; sand, Cyperus papyrus & 9.8 \\
\hline
\end{tabular}

Wetland degradation resulting from encroachment has got a number of effects/consequences and these range from physical, cultural, social and economic aspects. These consequences as noted from by respondents have been summarized in figure 5. Wetland degradation results into lowering of the water table which affects the soil capacity to sustain agriculture. There is a loss of aquatic biodiversity due to excessive harvesting and habitat destruction, local climatic modification in areas of drained wetlands, increased floods and occurrence of waterborne related diseases. The case of habitat destruction was so true as also recorded by Kansiime et al., [11] that the Papyrus Gonolek, a papyrus specialist bird, could not be found in areas where it was recorded in previous years, presumably because its habitat in Lubigi system had been destroyed. In the study area, wetland degradation has contributed to a number of socioeconomic effects and some of the common consequences have been recorded in this study as shown in figure 5 below. National working group 2 June 1995 indicated that "excavation of wetlands for sand mining or brick making leaves behind pits with stagnant water which are ideal breeding ground for disease vectors such as mosquitoes and snails". In addition wetland degradation results into the modification of the local microclimate. The consequence of wetland loss extends to aggravating climatic disturbances by increasing carbon build up in the atmosphere and biodiversity loss noted Gebresllassie [12]. Wetlands are the prominent shelter of aquatic and terrestrial biodiversity. Endemic fishes, birds and other life forms depend on wetlands. Hence, the loss of these wetlands is devastating to several endemic species and particularly to wetland-dependent species.

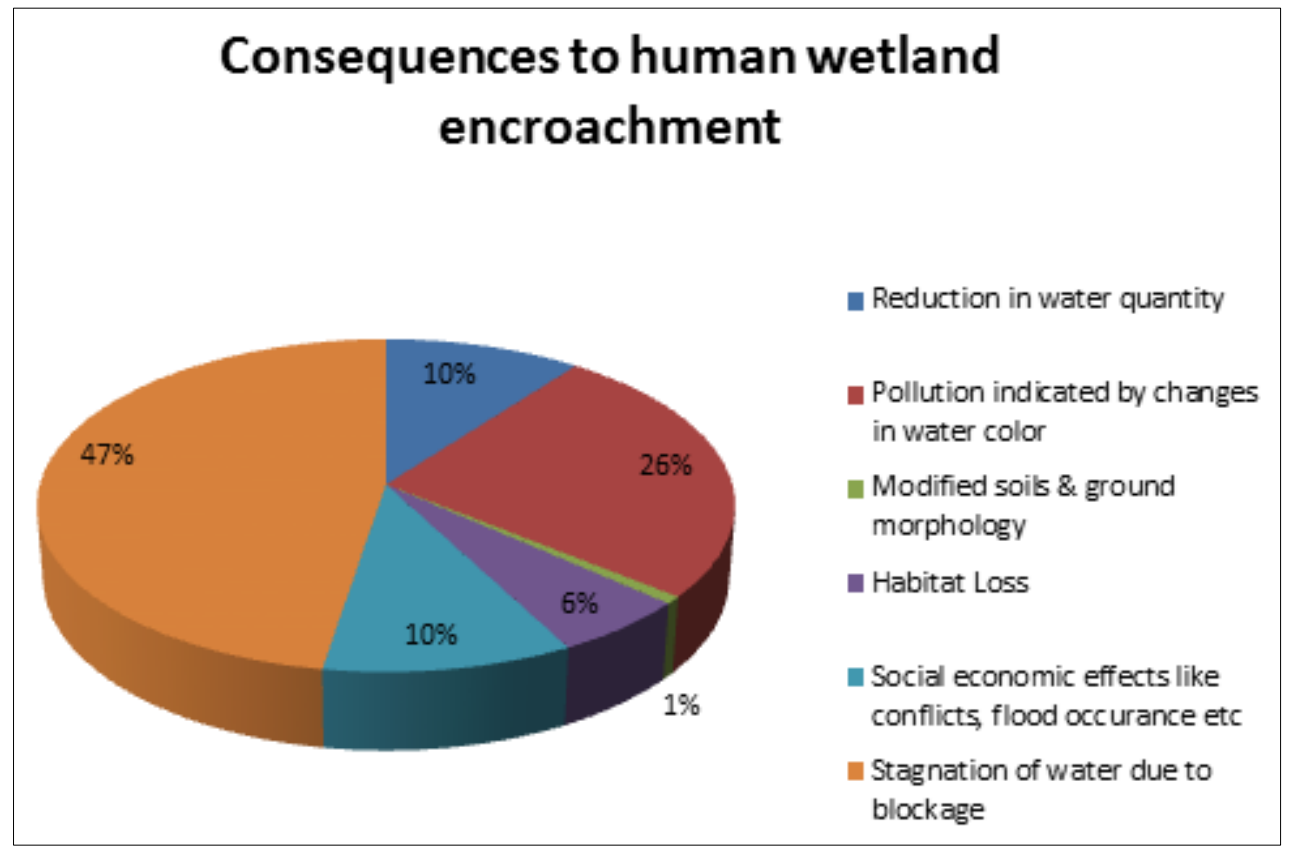

Figure 4. Most common consequences resulting from encroachment activities of the wetland System. 


\section{Conclusions}

From the findings of this research, a degraded and disturbed land cover pattern in this area of study is evident, with the change or disappearance of certain land cover elements as recorded by the help of GIS and RS hence showing the possibilities for monitoring wetlands with remote sensing. Monitoring wetlands like Lubigi seems certainly feasible but will require multi-spectral imagery with a resolution of 20 meter, but preferably less. These will probably pose their own specific requirements with respect to monitoring by means of remote sensing but will produce more profound and well-elaborated results.

Hence; the people settling around Lubigi wetland system are both the actors and spectators of the associated environmental degradation challenges; it thus needs the population of this area to assume responsibilities in guiding and controlling its development to safeguard the environment with the help of responsible government institutions like NEMA and NGO's in this same sector. This research shows that detection and evaluation of the causes and consequences of land cover change can lead to a possible proposal for a solution, one based on the geographic information system (GIS). In order to reverse these emerging problems and conserve these fragile but crucial wetlands, integrated problem-solving approach through realizing the collaboration of relevant stakeholders from policy level down to the grassroots community is an indispensable opportunity to Ugandan wetlands. Government, Communities, private sector and all others who have a stake in wetlands should cooperate and contribute their part. Decision makers at higher levels are required to strengthen sustainable wetland management efforts through effecting policy and legislation, improving institutional arrangements and supporting capacity building initiatives. It is appropriate to reassess the significance of wetlands and their environs for national development, and also the consequences of wetland degradation.

For the future studies; the recommendation can be finding high-resolution images and the multi-temporal ground truth data in order to increase the accuracy of the classification. Other factors to consider may include; building partnerships with stakeholders, monitoring upstream and downstream user relations and also the prioritization of prevailing management plans for wetlands. In consideration with the results obtained and previous studies carried out on this research area;

Stakeholders and those who live on or near wetlands need to become aware of how to properly and sustainably use the wetland. They need to be briefed on wise use methods of wetland protection so that they can live safely near wetlands and also feel empowered by their conservation. Road construction companies should be given clear guidelines by lead agencies responsible for issuing development permits on how to build and construct roads that still favour movement of water in and out of wetlands. This ensures that wetland ecosystem services still function to the benefit of the public.

The wetland boundary should be surveyed and the boundary outlined. In order to enable the sewage treatment plant work properly, the papyrus which is essential for sewage treatment should be replanted in areas where other land covers have already taken place. NWSC should consider funding papyrus replanting activities. As recommended by Kansiime et al., [13].

Further study is suggested to investigate detailed drivers and consequences of changes and use of high resolution and more detailed satellite images are recommended for further advancement in detailed studies with the use of GIS and RS tools.

A detailed biodiversity survey in the wetland needs to be carried out at an extensive scale to document species richness, abundance and monitoring in relation to what was observed in 2006 as recorded by Pomeroy [14] as this could further justify and show the impacts and worsening levels of degradation in the study area.

\section{Acknowledgements}

Part of this work was done as a final year research project at the Department of Environmental Science, Makerere University. Great thanks to all the lecturers for their constructive comments helping us to substantially improve our paper.

\section{REFERENCES}

[1] Samarasinghe YM, Dayawansa ND. A remote sensing and GIS based study in the assessment of the degradation risk of the Kolonnawa marsh. Journal of the National Science Foundation of Sri Lanka. 2013 Dec 13; 41(4).

[2] Barbier EB, Acreman M, Knowler D. Economic valuation of wetlands: a guide for policy makers and planners. Gland, Switzerland: Ramsar Convention Bureau.

[3] Bwogi, A. L. (2012). Wetlands Management. 2015, fromhttp://www.mwe.go.ug/index.php?option=com_conte nt\&view $=$ article\&id $=40 \&$ Itemid $=201$

[4] Abebe GA. Quantifying urban growth pattern in developing countries using remote sensing and spatial metrics: A case study in Kampala, Uganda. University of Twente Faculty of Geo-Information and Earth Observation (ITC); 2013 Feb.

[5] Ozesmi SL, Bauer ME. Satellite remote sensing of wetlands. Wetlands ecology and management. 2002 Oct 1; 10(5):381-402. 
[6] Maidment RI, Grimes DI, Allan RP, Greatrex H, Rojas O, Leo O. Evaluation of satellite-based and model re-analysis rainfall estimates for Uganda. Meteorological Applications. 2013 Sep 1; 20(3):308-17.

[7] Kansiime F, Kateyo E, Oryem-Origa H, Mucunguzi P. Nutrient status and retention in pristine and disturbed wetlands in Uganda: management implications. Wetlands Ecology and Management. 2007 Dec 1; 15(6):453- 67.

[8] Tilahun A, Teferie B. Accuracy assessment of land use land cover classification using Google Earth. American Journal of Environmental Protection. 2015; 4(4):193-8.

[9] Potere D. Horizontal positional accuracy of Google Earth's high-resolution imagery archive. Sensors. 2008 Dec 8; 8(12):7973-81.

[10] Mhonda AI. Evaluating flash flood risk reduction strategies in built-up environment in Kampala. University of Twente Faculty of Geo-Information and Earth Observation (ITC); 2013 Mar
[11] Tietenberg T, Victor DG. Possible administrative structures and procedures (for implementing a tradeable entitlement approach to controlling global warming). In combating global warming. Possible rules, regulations and administrative arrangements for a global market in $\mathrm{CO} 2$ emission entitlements 1994.

[12] Gebresllassie H, Gashaw T, Mehari A. Wetland degradation in Ethiopia: causes, consequences and remedies. Journal of environment and earth science. 2014; 4 (11):40-8.

[13] Kansiime F, Nalubega M, Van Bruggen JJ, Denny P. The effect of wastewater discharge on biomass production and nutrient content of Cyperus papyrus and Miscanthidium violaceum in the Nakivubo wetland, Kampala, Uganda. Water Science and Technology. 2003 Sep 1; 48(5):233.

[14] Pomeroy, R. K. a. D. Biodiversity of key sections of the proposed new Bujagali to Kampala transmission line. Makerere University: Makerere University 2003 (pp. 120). 